\title{
Prognostic Value of Restaging F-18 Fluorodeoxyglucose Positron Emission Tomography/Computed Tomography to Predict 3-Year Post-Recurrence Survival in Patients with Recurrent Gastric Cancer after Curative Resection
}

\author{
Sung Hoon Kim, $M D^{1,2}$, Bong-Il Song, $M D^{2}$, Hae Won Kim, $M D^{2}$, Kyoung Sook Won, $M D^{2}$, \\ Young-Gil Son, $M D^{3}$, Seung Wan Ryu, $M D^{3}$ \\ ${ }^{1}$ Department of Nuclear Medicine, Keimyung University Daegu Dongsan Hospital, Daegu, Korea; Departments of ${ }^{2}$ Nuclear Medicine and ${ }^{3}$ Surgery, \\ Keimyung University Dongsan Hospital, Keimyung University School of Medicine, Daegu, Korea
}

Objective: The aim of this study was to investigate the prognostic value of the maximum standardized uptake value $\left(S U V_{\max }\right)$ measured while restaging with F-18 fluorodeoxyglucose $\left({ }^{18} \mathrm{~F}-\mathrm{FDG}\right)$ positron emission tomography/computed tomography (PET/ $\mathrm{CT}$ ) to predict the 3-year post-recurrence survival (PRS) in patients with recurrent gastric cancer after curative surgical resection. Materials and Methods: In total, 47 patients with recurrent gastric cancer after curative resection who underwent restaging with ${ }^{18} \mathrm{~F}$-FDG PET/CT were included. For the semiquantitative analysis, $\mathrm{SUV}_{\max }$ was measured over the visually discernable ${ }^{18} \mathrm{~F}$-FDG-avid recurrent lesions. Cox proportional-hazards regression models were used to predict the 3-year PRS. Differences in 3-year PRS were assessed with the Kaplan-Meier analysis.

Results: Thirty-nine of the 47 patients (83\%) expired within 3 years after recurrence in the median follow-up period of 30.3 months. In the multivariate analysis, $\operatorname{SUV}_{\max }(p=0.012)$, weight loss $(p=0.025)$, and neutrophil count $(p=0.006)$ were significant prognostic factors for 3-year PRS. The Kaplan-Meier curves demonstrated significantly poor 3-year PRS in patients with $S U V_{\max }>5.1$ than in those with $S U V_{\max } \leq 5.1$ (3-year PRS rate, $3.5 \%$ vs. $38.9 \%, p<0.001$ ).

Conclusion: High SUV $\max$ on restaging with ${ }^{18} \mathrm{~F}-\mathrm{FDG} \mathrm{PET} / \mathrm{CT}$ is a poor prognostic factor for 3-year PRS. It may strengthen the role of ${ }^{18} \mathrm{~F}-\mathrm{FDG} \mathrm{PET} / \mathrm{CT}$ in further stratifying the prognosis of recurrent gastric cancer.

Keywords: Gastric cancer; PET/CT; FDG; Survival; Recurrence

\section{INTRODUCTION}

Gastric cancer is the sixth most common malignancy and the second leading cause of cancer deaths worldwide (1). Although the 5 year-overall survival (OS) rate is $62-71 \%$ in patients treated via surgery, a significant proportion of patients develop recurrences following resection $(2,3)$. Approximately $1 / 3$ of patients (35-42\%) still relapse after curative resection and adjuvant chemotherapy in Asian countries $(3,4)$. Hence, identifying relevant risk factors for patients with recurrent gastric cancer is crucial for predicting prognoses and future management strategies.

After experiencing a recurrence, most patients with gastric cancer have a poor prognosis and the majority dies within 3 years $(4,5)$. However, post-recurrence survival (PRS) time is variable among individual patients. Currently,

Received: September 6, 2019 Revised: February 19, 2020 Accepted: February 22, 2020

This study was supported by the National Research Foundation of Korea (NRF) grant funded by the Korea Government (MSIP) (No. 2014R1A5A2010008 and No. 2017R1C1B5076640).

Corresponding author: Bong-Il Song, MD, Department of Nuclear Medicine, Keimyung University Dongsan Hospital, Keimyung University School of Medicine, 1095 Dalgubeol-daero, Dalseo-gu, Daegu 42601, Korea.

- Tel: (8253) 258-7956•Fax: (8253) 258-4047• E-mail: song@dsmc.or.kr

This is an 0pen Access article distributed under the terms of the Creative Commons Attribution Non-Commercial License (https:// creativecommons.org/licenses/by-nc/4.0) which permits unrestricted non-commercial use, distribution, and reproduction in any medium, provided the original work is properly cited. 
most studies have dealt with prognostic factors for OS or disease-free survival (DFS) in gastric cancer; thus, many clinicopathological parameters including age, sex, histology, number of metastatic and retrieved lymph nodes (LNs), inflammatory markers, or nutritional risks beyond the tumor-node-metastasis (TNM) stage are currently available for predicting survival outcomes (6-9). However, few studies to date have focused on PRS in patients with recurrent gastric cancer and little is known about predictive factors that affect a patient's prognosis after recurrence.

Positron emission tomography/computed tomography (PET/CT) with F-18 fluorodeoxyglucose $\left({ }^{18} \mathrm{~F}-\mathrm{FDG}\right)$ has been widely used for staging, evaluating treatment response, and detecting disease recurrence in gastric cancer (10). Notably, ${ }^{18} \mathrm{~F}$-FDG uptake reflects the biological aggressiveness of gastric cancer; increases have been found to be an independent prognostic marker for patient outcomes in terms of OS or DFS (11). Several studies demonstrated the prognostic value of semi-quantitative ${ }^{18} \mathrm{~F}$-FDG uptake of the primary tumor or metastatic $L N$ in patients with various stages of gastric cancer (12-15). However, it remains uncertain whether the glycolytic activity of recurrent tumors could provide prognostic information regarding recurrent gastric cancer. Although diagnostic value of surveillance or restaging using ${ }^{18} \mathrm{~F}-\mathrm{FDG} \mathrm{PET} / \mathrm{CT}$ has been reported by previous studies (16-18), there are no reports focused on metabolic activity derived from the ${ }^{18} \mathrm{~F}-\mathrm{FDG}$ PET/ CT restaging scan as a prognostic marker for PRS in patients with recurrent gastric cancer.

Therefore, we aimed to investigate the prognostic impact of the maximum standardized uptake value $\left(S_{U} U V_{\max }\right)$ measured by ${ }^{18} \mathrm{~F}-\mathrm{FDG} \mathrm{PET} / \mathrm{CT}$ restaging scans to predict 3-year PRS in patients with recurrent gastric cancer after curative surgical resection.

\section{MATERIALS AND METHODS}

This study followed the medical research protocols and ethical guidelines laid down by the World Medical Association's Declaration of Helsinki. The retrospective study protocol was approved by the Institutional Review Board (\#2018-06-028), and the need for written informed consent was waived.

\section{Patients}

Study participants were selected from 1101 patients with stomach cancer who received potentially curative gastrectomy at our institution between January 2008 and December 2011. The exclusion criteria were non-curative surgery (microscopic or macroscopic residual disease [R1R2] after resection), the presence of distant metastasis, the reception of any other treatment prior to surgery, a history of previous malignancy, the presence of synchronous malignancy, no recurrence during follow-up, or the absence of ${ }^{18} \mathrm{~F}-\mathrm{FDG}$ PET/CT restaging scans. Finally, 47 patients with recurrent gastric cancer who underwent ${ }^{18} \mathrm{~F}$-FDG PET/CT restaging scans were enrolled in this study.

All patients received total or subtotal gastrectomy along with D2 lymphadenectomy (advanced gastric cancer [AGC]) and $\mathrm{D} 1+\beta$ or $\mathrm{D} 2$ lymphadenectomy (early gastric cancer [EGC]). Patients had routinely been followed up every 3 months for the first year after surgery. Subsequently, patients with $\mathrm{EGC}$ were followed up every 6 months until 3 years while those with AGC were followed up every 6 months until 5 years. Finally, they were followed up annually using clinical and laboratory examinations with imaging and endoscopic evaluations.

\section{Clinicopathologic and Survival Data}

Clinicopathologic data, including sex, age, body weight at surgery and recurrence, percentage of weight loss, surgical and perioperative findings (e.g., type of gastrectomy, pathologic $\mathrm{T}[\mathrm{pT}]$, pathologic $\mathrm{N}[\mathrm{pN}]$ and TNM stages, histopathological subtypes, Lauren histotypes, ratio of the number of metastatic LNs to the total number of harvested LNs $[\mathrm{LNR}])$, laboratory values at recurrence, and survival were reviewed and documented. The $\mathrm{pT}, \mathrm{pN}$, and TNM stages were classified according to the 8th American Joint Committee on Cancer staging system (19). Neutrophil counts, lymphocyte counts, platelet counts, and hemoglobin levels were obtained at the time of recurrence.

The date of recurrence was defined as follows: the date of imaging examination when imaging findings were used for a definitive diagnosis or the date, when an imaging modality showed abnormal findings for the first time when recurrence was histologically confirmed (20). PRS was defined as the time from the date of recurrence to the date of death; the remaining patients were censored at the last follow-up date that occurred in our institution.

\section{${ }^{18}$ F-FDG PET/CT Scan and Image Analysis}

All participants performed ${ }^{18} \mathrm{~F}-\mathrm{FDG}$ PET/CT scans using two integrated PET/CT scanners (Discovery STE; GE Healthcare, Milwaukee, WI, USA or Biograph mCT; Siemens Healthineers 
Knoxville, TN, USA). Before ${ }^{18} \mathrm{~F}$-FDG injection, all patients fasted for at least 6 hours and the blood glucose level of $<150 \mathrm{mg} / \mathrm{dL}$ was maintained. Patients were encouraged to rest during the ${ }^{18} \mathrm{~F}-\mathrm{FDG}$ uptake period. Images were acquired 60 minutes after $5.5 \mathrm{MBq} / \mathrm{kg}$ (Discovery STE) or $4.0 \mathrm{MBq} /$ $\mathrm{kg}$ (Biograph $\mathrm{mCT}$ ) of FDG was administered intravenously. A low-dose CT scan (Discovery STE; peak voltage of $120 \mathrm{kVp}$ and slice thickness of $3.75 \mathrm{~mm}$, Biograph $\mathrm{mCT}$; peak voltage of $120 \mathrm{kVp}$ and slice thickness of $3 \mathrm{~mm}$ ) was acquired, and PET scan was obtained with an acquisition time of 3 $\mathrm{min} /$ bed position with the Discovery STE and $1.5 \mathrm{~min} /$ bed position with the Biograph $\mathrm{mCT}$ in 3-dimensional mode. Images were reconstructed via ordered-subset expectation maximum iterative reconstruction with attenuation correction.

The images were retrospectively interpreted on an Advantage Workstation 4.3 (GE Healthcare) by two boardcertified nuclear medicine physicians. Both readers had knowledge of all available imaging studies; however, they were blinded to the patients' survival data. For the semiquantitative analysis, SUV ${ }_{\max }$ was measured by manually placing circular regions of interest over the visually discernable ${ }^{18} \mathrm{~F}-\mathrm{FDG}$ avid metastatic lesions on the attenuation-corrected transaxial ${ }^{18} \mathrm{~F}$-FDG PET images. To evaluate patients with anastomotic recurrence, abnormally increased uptake at the anastomosis site corresponding to endoscopic and histopathological findings was considered as a recurring malignant lesion. The SUV $V_{\max }$ was calculated using the following formula: $\mathrm{SUV}_{\max }=$ maximum activity in the region of interest $(\mathrm{MBq} / \mathrm{g}) /$ (injected dose $[\mathrm{MBq}] /$ body weight $[\mathrm{g}])$.

\section{Statistical Analyses}

Numeric data are expressed as medians and interquartile ranges (IQRs), while categorical variables are reported as numbers and percentages. The optimal cutoff values for continuous variables for 3-year PRS predictions were derived from maximally selected chi-square statistics using $R$ package 'Maxstat' (21). Recurrence timing was divided into early ( $\leq 2$ years from the surgery date) and late ( $>2$ years from the surgery date) (22). The Kaplan-Meier method was used to estimate the 3 -year PRS rate. All $p$ values $<0.05$ were considered statistically significant. For investigating predictive parameters affecting 3-year PRS, multivariate Cox proportional-hazards regression models were performed with the stepwise approach. Variables with $p$ value $<0.05$ in the univariate analysis were selected for multivariate analysis; the hazards ratio (HR) and 95\% confidence interval (CI) were estimated for each parameter. Statistical analyses were performed using MedCalc for Windows, version 18.10.2 (MedCalc Software, Ostend, Belgium) and R version 3.4.3 software (http://www.r-project.org, R Foundation for Statistical Computing, Vienna, Austria).

\section{RESULTS}

\section{Patient Characteristics}

In total, 47 patients with recurrent gastric cancer who received curative surgical resection were retrospectively analyzed. Recurrence was confirmed histologically in 33 $(70.2 \%)$ of the 47 patients, and clinically diagnosed in the remaining 14 patients $(29.8 \%)$. Overall, 39 of the 47 patients $(83.0 \%)$ were confirmed dead within 3 years after recurrence during the median follow-up period of 30.3 months (IQR, 18.1-62.6 months), and 3-year PRS rates were $17.0 \%$.

The median PRS time was 10.0 months (IQR, 4.7-19.8 months) in all patients, 50.7 months (IQR, 40.3-71.8 months) in patients who survived over 3 years while 7.7 months (IQR, 4.5-12.4 months) in those who died within 3 years. The median $S U V_{\max }$ obtained from restaging ${ }^{18} \mathrm{~F}-\mathrm{FDG}$ $\mathrm{PET} / \mathrm{CT}$ scans were 4.0 (IQR, 3.3-4.7) in patients surviving over 3 years and 7.3 (IQR, 5.0-9.9) in those who died within 3 years.

The characteristics of the enrolled patients (median age, 59.0 years; IQR, 46.0-64.5 years) are listed in Table 1. Most patients were diagnosed with AGC (89.4\%) while only five patients had EGC (10.6\%). Pathologic TNM stage III was most frequently observed (63.9\%). According to the World Health Organization classification, 31 patients (66.0\%) were categorized as having adenocarcinoma (30 tubular and 1 mucinous types) and $16(34.0 \%)$ had a signet ring cell type. In terms of the Lauren histotype, 33 patients (70.2\%) were diffuse and 14 (29.8\%) were intestinal.

The median time to recurrence (i.e., DFS) was 17.8 months (IQR, 12.4-35.9 months), and a significant portion of patients $(63.9 \%)$ recurred within 2 years. Six of the 47 patients $(12.8 \%)$ experienced locoregional recurrence, 31 $(65.9 \%)$ had distant metastasis, and 10 (21.3\%) developed both locoregional and distant failure at the time of recurrence. Most frequent patterns of distant metastasis were hematogenous $(60.0 \%)$, followed by peritoneal recurrence $(18.3 \%)$, and then lymphatic metastasis (16.7\%). The therapeutic aim of recurrent disease was as follows: 12 patients $(25.5 \%)$ underwent potentially curative treatment, 
27 patients $(57.5 \%)$ underwent palliative treatment, and the remaining eight patients $(17.0 \%)$ received only supportive care.
Uni- and Multivariate Analyses

The optimal cutoff values of patients' age, LNR, SUV ${ }_{\max }$, weight loss percentage, and hemoglobin level as well as

Table 1. Patient Characteristics Depending on 3-Year Post-Recurrence Survival Status

\begin{tabular}{|c|c|c|c|c|}
\hline Variables & $\begin{array}{c}\text { Total }(\mathrm{n}=47) \\
\mathrm{n}(\%) \text { or Median (IQR) }\end{array}$ & $\begin{array}{c}\text { Live More than } \\
3 \text { Years after Recurrence }(n=8) \\
n(\%) \text { or Median (IQR) }\end{array}$ & $\begin{array}{c}\text { Death within } \\
3 \text { Years after Recurrence }(n=39) \\
n(\%) \text { or Median }(I Q R)\end{array}$ & $P$ \\
\hline Age at diagnosis, years & $59.0(46.0-64.5)$ & $55.5(47.5-65.5)$ & $59.0(46.0-64.0)$ & 0.723 \\
\hline Sex & & & & 0.146 \\
\hline Male & $31(66.0)$ & $3(37.5)$ & $28(71.8)$ & \\
\hline Female & $16(34.0)$ & $5(62.5)$ & $11(28.2)$ & \\
\hline Type of gastrectomy & & & & 0.536 \\
\hline Total & $13(27.7)$ & $1(12.5)$ & $12(30.8)$ & \\
\hline Subtotal & $34(72.3)$ & $7(87.5)$ & $27(69.2)$ & \\
\hline Pathologic T stage* & & & & 0.328 \\
\hline $\mathrm{T} 1$ & $5(10.6)$ & $2(25.0)$ & $3(7.7)$ & \\
\hline T2 & $6(12.8)$ & $1(12.5)$ & $5(12.8)$ & \\
\hline T3 & $7(14.9)$ & $2(25.0)$ & $5(12.8)$ & \\
\hline T4 & $29(61.7)$ & $3(37.5)$ & $26(66.7)$ & \\
\hline Pathologic N stage* & & & & 0.203 \\
\hline NO & $12(25.5)$ & $4(50.0)$ & $8(20.5)$ & \\
\hline N1 & $3(6.4)$ & $1(12.5)$ & $2(5.1)$ & \\
\hline N2 & $6(12.8)$ & $0(0.0)$ & $6(15.4)$ & \\
\hline N3 & $26(55.3)$ & $3(37.5)$ & $23(59.0)$ & \\
\hline TNM stage* & & & & 0.178 \\
\hline I & $5(10.6)$ & $2(25.0)$ & $3(7.7)$ & \\
\hline II & $12(25.5)$ & $3(37.5)$ & $9(23.1)$ & \\
\hline III & $30(63.9)$ & $3(37.5)$ & $27(69.2)$ & \\
\hline Histopathologic subtype & & & & 0.759 \\
\hline Adenocarcinoma & $31(66.0)$ & $6(75.0)$ & $25(64.1)$ & \\
\hline Signet ring cell & $16(34.0)$ & $2(25.0)$ & $14(35.9)$ & \\
\hline Lauren histotype & & & & 0.343 \\
\hline Diffuse & $33(70.2)$ & $4(50.0)$ & $29(74.4)$ & \\
\hline Intestinal & $14(29.8)$ & $4(50.0)$ & $10(25.6)$ & \\
\hline LNR & $0.11(0.01-0.33)$ & $0.01(0.00-0.33)$ & $0.11(0.05-0.33)$ & 0.311 \\
\hline $\mathrm{SUV}_{\max }$ & $6.3(4.2-9.2)$ & $4.0(3.3-4.7)$ & $7.3(5.0-9.9)$ & 0.015 \\
\hline Weight loss, $\%$ & $11.6(8.6-15.8)$ & $10.3(5.0-13.9)$ & $11.6(9.8-17.5)$ & 0.130 \\
\hline Hemoglobin, g/dL & $11.7(11.1-12.6)$ & $11.8(11.6-12.1)$ & $11.7(10.9-12.6)$ & 0.671 \\
\hline Neutrophil count, cells/uL & 3503 (2601-4894) & 2742 (2298-3497) & 3934 (2691-5338) & 0.125 \\
\hline Lymphocyte count, cells/uL & 1317 (964-1739) & 1235 (869-1875) & 1335 (964-1739) & 0.588 \\
\hline Platelet count, $\times 10^{3}$ cells $/ \mathrm{uL}$ & $228(193-275)$ & $221(191-268)$ & $231(193-278)$ & 0.887 \\
\hline Recurrence timing & & & & 0.035 \\
\hline Early, $\leq 2$ years & $30(63.9)$ & $2(25.0)$ & $28(71.8)$ & \\
\hline Late, $>2$ years & $17(36.1)$ & $6(75.0)$ & $11(28.2)$ & \\
\hline First sites of recurrence & & & & 0.192 \\
\hline Locoregional recurrence only & $6(12.8)$ & $2(25.0)$ & $4(10.3)$ & \\
\hline Distant metastasis only & $31(65.9)$ & $6(75.0)$ & $25(64.1)$ & \\
\hline Locoregional and distant failure & $10(21.3)$ & $0(0.0)$ & $10(25.6)$ & \\
\hline
\end{tabular}

${ }^{*}$ According to 8th AJCC staging system. AJCC $=$ American Joint Committee on Cancer, IQR = interquartile range, LNR $=$ ratio of number of metastatic lymph nodes to total number of harvested lymph nodes, SUV $_{\max }=$ maximum standardized uptake value, TNM $=$ tumor-nodemetastasis 
for the neutrophil, lymphocyte and platelet counts for a 3-year PRS were 50, 0.063, 5.1, 14.7, 11.4, 2997, 1084, and 154000 , respectively. SUV max $_{\text {max }}$ performed a KaplanMeier analysis with a log-rank test to compare 3-year PRS stratification. Notably, high SUV max $_{\text {was }}$ associated with a significantly lower 3-year PRS rate compared to low SUV ${ }_{\max }$ (3.5\% vs. $38.9 \%, p<0.001)$ (Fig. 1).

Values above and below the optimal cutoff for LNR, SUV $\max$, weight loss, neutrophil count, and recurrence timing were significantly associated with 3-year PRS in the univariate Cox proportional-hazards regression analysis (Table 2). In the multivariate analysis, $\mathrm{SUV}_{\max }(\mathrm{HR}, 2.57 ; 95 \% \mathrm{CI}, 1.16-$ $5.69 ; p=0.012)$, weight loss (HR, 2.24; 95\% CI, 1.11-4.56; $p=0.025)$, and neutrophil count (HR, 2.68; 95\% CI, 1.32$5.43 ; p=0.006$ ) were independently prognostic for 3-year PRS. However, the LNR and recurrence timing were no longer statistically significant in the multivariate analysis. A visual presentation of independent prognostic factors for each study participant is displayed in Figure 2.

\section{DISCUSSION}

In the current study, we assessed the prognostic value of



Fig. 1. Cumulative PRS curves of 47 patients with recurrent gastric cancer stratified by SUV max $_{\text {. High SUV }}$ max was associated with significantly lower 3-year PRS rate compared to low SUV max $_{\text {ax }}$ $(3.5 \%$ vs. $38.9 \%, p<0.001)$. PRS = post-recurrence survival, $\mathrm{SUV}_{\max }=$ maximum standardized uptake value
$\mathrm{SUV}_{\text {max }}$ on ${ }^{18} \mathrm{~F}$-FDG PET/CT in patients with recurrent gastric cancer after curative surgical resection. Several studies have reported the prognostic factors for PRS in a variety of malignancies, including stomach, breast, hepatocellular, cervical, and non-small-cell lung cancers (23-26). However, to the best of our knowledge, no studies have established the prognostic value of ${ }^{18} \mathrm{~F}-\mathrm{FDG}$ PET/CT after recurrence in the field of gastric cancer. Our results demonstrated that the SUV $V_{\max }$ was an independent survival predictor for 3-year PRS in the multivariate analysis.

Death after recurrence usually occurs rapidly even after achieving curative intent resection. Despite more than $80 \%$ of patients dying within 3 years following a recurrence $(4,5)$, there were some long-term survivors. In our study, $17 \%$ of the patients lived more than 3 years after relapse and their median PRS was over 50 months. In that regard, predicting patient outcomes after recurrence might be helpful for creating a personalized therapeutic approach or in follow-up planning. Hence, our results suggest a potential value of SUV $V_{\text {max }}$ for further prognostication in patients with recurrent gastric cancer. The SUV max $_{\text {, a simple }}$ measurement and the most widely used metabolic parameter obtained by ${ }^{18} \mathrm{~F}$-FDG PET/CT (27), consistently estimated 3-year PRS outcomes. This may be because increased ${ }^{18} \mathrm{~F}-\mathrm{FDG}$ uptake reflects biological aggressiveness not only the initial staging of gastric cancer but also in cases of recurrence $(13,28)$. Thus, ${ }^{18} \mathrm{~F}-\mathrm{FDG} \mathrm{PET} / \mathrm{CT}$ seems to play an additional prognostication role in patients with recurrent disease regarding their survival and in detecting recurrence.

Inflammatory response to cancer contributes to carcinogenesis and tumor progression. Therefore, inflammatory biomarkers have recently been evaluated as valuable prognostic factors in various type of cancers (29); moreover, the neutrophil-to-lymphocyte ratio (NLR) and platelet-to-lymphocyte ratio (PLR) have been widely evaluated for prognostication in gastric cancers (30). Some studies reported NLR to be more predictive for prognoses than PLR $(31,32)$. More recently, Guner et al. (9) demonstrated that simple parameters (e.g., neutrophil count) are better for predicting short- and long-term outcomes in patients with surgically resected gastric cancers compared to complex parameters (e.g., NLR). Our findings show that high neutrophil counts upon recurrence were associated with poor prognoses in patients with relapsed gastric cancer.

The percentage of weight loss, as a simple nutritional parameter, was also an independent survival predictor for 
Table 2. Univariate and Multivariate Analyses for 3-Year Post-Recurrence Survival

\begin{tabular}{|c|c|c|c|c|}
\hline \multirow{2}{*}{ Variables } & \multicolumn{2}{|c|}{ Univariate Analysis } & \multicolumn{2}{|c|}{ Multivariate Analysis } \\
\hline & $\mathrm{HR}(95 \% \mathrm{CI})$ & $P$ & $\mathrm{HR}(95 \% \mathrm{CI})$ & $P$ \\
\hline \multicolumn{5}{|l|}{ Age at diagnosis, years } \\
\hline \multicolumn{5}{|l|}{$<50^{*}$} \\
\hline$\geq 50$ & $1.57(0.80-3.06)$ & 0.187 & & \\
\hline \multicolumn{5}{|l|}{ Sex } \\
\hline \multicolumn{5}{|l|}{ Male* } \\
\hline Female & $0.54(0.27-1.09)$ & 0.086 & & \\
\hline \multicolumn{5}{|l|}{ Type of gastrectomy } \\
\hline \multicolumn{5}{|l|}{ Total* } \\
\hline Subtotal & $0.69(0.35-1.36)$ & 0.282 & & \\
\hline \multicolumn{5}{|l|}{ Pathologic T stage ${ }^{\dagger}$} \\
\hline \multicolumn{5}{|l|}{$\mathrm{T} 1^{*}$} \\
\hline $\mathrm{T} 2$ & $1.35(0.32-5.71)$ & 0.682 & & \\
\hline T3 & $0.86(0.21-3.61)$ & 0.837 & & \\
\hline T4 & $1.77(0.53-5.89)$ & 0.355 & & \\
\hline \multicolumn{5}{|l|}{ Pathologic N stage ${ }^{\dagger}$} \\
\hline \multicolumn{5}{|l|}{ No* } \\
\hline N1 & $0.78(0.17-3.69)$ & 0.754 & & \\
\hline N2 & $2.39(0.79-7.13)$ & 0.119 & & \\
\hline N3 & $2.01(0.89-4.51)$ & 0.091 & & \\
\hline \multicolumn{5}{|l|}{ TNM stage $^{\dagger}$} \\
\hline \multicolumn{5}{|l|}{$I^{*}$} \\
\hline II & $0.95(0.26-3.53)$ & 0.942 & & \\
\hline III & $1.79(0.54-5.97)$ & 0.337 & & \\
\hline \multicolumn{5}{|l|}{ Histopathologic subtype } \\
\hline \multicolumn{5}{|l|}{ Adenocarcinoma* } \\
\hline Signet ring cell & $1.26(0.65-2.43)$ & 0.493 & & \\
\hline \multicolumn{5}{|l|}{ Lauren histotype } \\
\hline \multicolumn{5}{|l|}{ Diffuse* } \\
\hline Intestinal & $0.68(0.33-1.41)$ & 0.298 & & \\
\hline \multicolumn{5}{|l|}{ LNR } \\
\hline \multicolumn{5}{|l|}{$\leq 0.063^{*}$} \\
\hline$>0.063$ & $2.22(1.12-4.43)$ & 0.023 & & \\
\hline \multicolumn{5}{|l|}{ SUV $_{\max }$} \\
\hline$\leq 5.1^{*}$ & & & & \\
\hline$>5.1$ & $3.30(1.58-6.87)$ & 0.001 & $2.57(1.16-5.69)$ & 0.012 \\
\hline Weight loss, \% & & & & \\
\hline$\leq 14.7^{*}$ & & & & \\
\hline$>14.7$ & $2.91(1.48-5.71)$ & 0.002 & $2.24(1.11-4.56)$ & 0.025 \\
\hline Hemoglobin, g/dL & & & & \\
\hline$\geq 11.4^{*}$ & & & & \\
\hline$<11.4$ & $1.88(0.98-3.58)$ & 0.055 & & \\
\hline Neutrophil count, cells/uL & & & & \\
\hline$\leq 2997^{*}$ & & & & \\
\hline$>2997$ & $2.89(1.45-5.79)$ & 0.003 & $2.68(1.32-5.43)$ & 0.006 \\
\hline Lymphocyte count, cells/ul & & & & \\
\hline$\leq 1084^{*}$ & & & & \\
\hline$>1084$ & $0.58(0.30-1.10)$ & 0.095 & & \\
\hline
\end{tabular}


Table 2. Univariate and Multivariate Analyses for 3-Year Post-Recurrence Survival (Continued)

\begin{tabular}{|c|c|c|c|c|}
\hline \multirow{2}{*}{ Variables } & \multicolumn{2}{|c|}{ Univariate Analysis } & \multicolumn{2}{|c|}{ Multivariate Analysis } \\
\hline & $\operatorname{HR}(95 \% \mathrm{CI})$ & $P$ & $\mathrm{HR}(95 \% \mathrm{CI})$ & $P$ \\
\hline \multicolumn{5}{|l|}{ Platelet count, cells/uL } \\
\hline \multicolumn{5}{|l|}{$\geq 154000^{*}$} \\
\hline$<154000$ & $2.16(0.88-5.31)$ & 0.094 & & \\
\hline \multicolumn{5}{|l|}{ Recurrence timing } \\
\hline Early,$\leq 2$ years & $2.40(1.18-4.91)$ & 0.016 & & \\
\hline \multicolumn{5}{|l|}{ Late, $>2$ years* } \\
\hline \multicolumn{5}{|l|}{ First sites of recurrence } \\
\hline \multicolumn{5}{|l|}{ Locoregional recurrence only* } \\
\hline Distant metastasis only & $1.49(0.52-4.31)$ & 0.458 & & \\
\hline Locoregional and distant failure & $2.62(0.81-8.41)$ & 0.107 & & \\
\hline
\end{tabular}

${ }^{*}$ Reference of categorical parameter, ${ }^{\dagger}$ According to 8 th $\mathrm{AJCC}$ staging system. $\mathrm{CI}=$ confidence interval, $\mathrm{HR}=$ hazard ratio



Fig. 2. Visual summary of independent prognostic factors in series of $\mathbf{4 7}$ patients. Red color indicates patients who died within 3 years after recurrence, and blue color indicates those who survived. Overall survival time after recurrence and numeric data of each parameter are depicted on 4-color scale.

PRS in the present study. Weight loss can be an indicator of malnutrition and is closely associated with patients' postoperative quality of life (33). Aoyama et al. (34) found that postoperative weight loss $\geq 15 \%$ could lead to worse survival outcomes through a significantly decreased compliance of adjuvant treatments. As appropriate nutritional care could improve survival after recurrence and significantly reduce patients' perioperative morbidity and mortality (35), further studies applying appropriate nutritional assessment tools might help validate whether the patient's nutritional status could affect PRS or not.

Increased glucose consumption and glycolysis are critical hallmarks of gastric cancer; therapeutically targeting tumor cell metabolism processes, such as glucose metabolism, is more convenient approach and is associated with fewer side effects than targeting other biologic systems since cellular metabolic pathways represent the terminus of biologic systems and control the other systems genetically $(36,37)$. Thus, anti-tumor therapies targeting this aspect of cancer are new and appear promising. There have been several studies on therapies reducing glucose consumption of gastric cancer cells (38), suppressing hexokinase II
$(39,40)$, or blocking the Warburg effect in combination with other therapies (41) in in vitro and preclinical in vivo settings. As glycolysis-targeted or other novel antitumor therapies are discovered, the application of ${ }^{18} \mathrm{~F}-\mathrm{FDG}$ $\mathrm{PET} / \mathrm{CT}$, a clinical imaging surrogate for enhanced glucose metabolism, could be a considerable strategy to evaluate therapeutic responses and prognostication in recurrent gastric cancer.

The present study had some limitations. The retrospective nature and the relatively small patient dataset from a single institution were the main limitations; these might also have subjected the study to selection bias. Moreover, patients with recurrent cancer who did not undergo ${ }^{18} \mathrm{~F}$-FDG PET/CT scans were not included. However, our study suggests the potential value of ${ }^{18} \mathrm{~F}$-FDG uptake for further prognostication in patients with recurrent gastric cancer. In addition, two different PET/CT scanners (Discovery STE and Biograph mCT) were used. The difference in the resolution and administered ${ }^{18}$ F-FDG doses could have affected SUV $_{\max }$ values. However, a prior study has validated that the difference in the SUV $V_{\max }$ values of the same lesion between two different scanners is $<0.05$ (42). Despite these limitations, we suggest that 
${ }^{18} \mathrm{~F}$-FDG uptake at recurrence might be helpful in predicting survival outcomes in patients with recurrent gastric cancer. Further large-scale prospective studies should be conducted using ${ }^{18} \mathrm{~F}$-FDG PET/CT to assess the prognostic value in recurrent gastric cancer.

In conclusion, the present study revealed that SUV $V_{\max }$ could estimate survival outcomes in patients with recurrent gastric cancer after curative resection. Thus, restaging ${ }^{18} \mathrm{~F}$-FDG PET/CT scans could be used to estimate life expectancy after recurrence and may bolster the role of ${ }^{18} \mathrm{~F}-\mathrm{FDG} \mathrm{PET} / \mathrm{CT}$ in oncology practice.

\section{Conflicts of Interest}

The authors have no potential conflicts of interest to disclose.

\section{ORCID iDs}

Bong-Il Song
https://orcid.org/0000-0002-3106-6112
Sung Hoon Kim
https://orcid.org/0000-0002-1024-1153
Hae Won Kim
https://orcid.org/0000-0002-6707-3904
Kyoung Sook Won
https://orcid.org/0000-0001-7185-911X
Young-Gil Son
https://orcid.org/0000-0001-9088-6519
Seung Wan Ryu
https://orcid.org/0000-0003-0374-5748

\section{REFERENCES}

1. Bray F, Ferlay J, Soerjomataram I, Siegel RL, Torre LA, Jemal A. Global cancer statistics 2018: GLOBOCAN estimates of incidence and mortality worldwide for 36 cancers in 185 countries. CA Cancer J Clin 2018;68:394-424

2. Katai H, Ishikawa T, Akazawa K, Isobe Y, Miyashiro I, Oda $\mathrm{I}$, et al. Five-year survival analysis of surgically resected gastric cancer cases in Japan: a retrospective analysis of more than 100,000 patients from the nationwide registry of the Japanese Gastric Cancer Association (2001-2007). Gastric Cancer 2018;21:144-154

3. Moon YW, Jeung HC, Rha SY, Yoo NC, Roh JK, Noh SH, et al. Changing patterns of prognosticators during 15-year followup of advanced gastric cancer after radical gastrectomy and adjuvant chemotherapy: a 15-year follow-up study at a single Korean institute. Ann Surg Oncol 2007;14:2730-2737

4. Ito $S$, Ohashi $Y$, Sasako M. Survival after recurrence in patients with gastric cancer who receive S-1 adjuvant chemotherapy: exploratory analysis of the ACTS-GC trial. BMC Cancer 2018;18:449

5. Spolverato G, Ejaz A, Kim Y, Squires MH, Poultsides GA, Fields $\mathrm{RC}$, et al. Rates and patterns of recurrence after curative intent resection for gastric cancer: a United States multiinstitutional analysis. J Am Coll Surg 2014;219:664-675

6. Kattan MW, Karpeh MS, Mazumdar M, Brennan MF. Postoperative nomogram for disease-specific survival after an R0 resection for gastric carcinoma. J Clin Oncol 2003;21:36473650

7. Han DS, Suh YS, Kong SH, Lee HJ, Choi Y, Aikou S, et al. Nomogram predicting long-term survival after d2 gastrectomy for gastric cancer. J Clin Oncol 2012;30:3834-3840

8. Woo Y, Son T, Song K, Okumura N, Hu Y, Cho GS, et al. A novel prediction model of prognosis after gastrectomy for gastric carcinoma: development and validation using Asian databases. Ann Surg 2016;264:114-120

9. Guner A, Kim SY, Yu JE, Min IK, Roh YH, Roh C, et al. Parameters for predicting surgical outcomes for gastric cancer patients: simple is better than complex. Ann Surg Oncol 2018;25:3239-3247

10. Marcus C, Subramaniam RM. PET/computed tomography and precision medicine: gastric cancer. PET Clin 2017;12:437-447

11. Yun M. Imaging of gastric cancer metabolism using 18 F-FDG PET/CT. J Gastric Cancer 2014;14:1-6

12. Lee JW, Lee SM, Lee MS, Shin HC. Role of ${ }^{18} \mathrm{~F}-\mathrm{FDG}$ PET/CT in the prediction of gastric cancer recurrence after curative surgical resection. Eur J Nucl Med Mol Imaging 2012;39:14251434

13. Park JC, Lee JH, Cheoi K, Chung H, Yun MJ, Lee $H$, et al. Predictive value of pretreatment metabolic activity measured by fluorodeoxyglucose positron emission tomography in patients with metastatic advanced gastric cancer: the maximal SUV of the stomach is a prognostic factor. Eur J Nucl Med Mol Imaging 2012;39:1107-1116

14. Kim J, Lim ST, Na CJ, Han YH, Kim CY, Jeong HJ, et al. Pretreatment F-18 FDG PET/CT parameters to evaluate progression-free survival in gastric cancer. Nucl Med Mol Imaging 2014;48:33-40

15. Song BI, Kim HW, Won KS, Ryu SW, Sohn SS, Kang YN. Preoperative standardized uptake value of metastatic lymph nodes measured by ${ }^{18} \mathrm{~F}-\mathrm{FDG}$ PET/CT improves the prediction of prognosis in gastric cancer. Medicine (Baltimore) 2015;94:e1037

16. Lee JE, Hong SP, Ahn DH, Jeon TJ, Kang MK, Kwon CI, et al. The role of ${ }^{18} \mathrm{~F}-\mathrm{FDG} \mathrm{PET} / \mathrm{CT}$ in the evaluation of gastric cancer recurrence after curative gastrectomy. Yonsei Med J 2011;52:81-88

17. Cayvarlı H, Bekiş R, Akman T, Altun D. The role of 18F-FDG $\mathrm{PET} / \mathrm{CT}$ in the evaluation of gastric cancer recurrence. Mol Imaging Radionucl Ther 2014;23:76-83

18. Kim SJ, Cho YS, Moon SH, Bae JM, Kim S, Choe YS, et al. Primary tumor ${ }^{18} \mathrm{~F}-\mathrm{FDG}$ avidity affects the performance of ${ }^{18}$ F-FDG PET/CT for detecting gastric cancer recurrence. J Nucl 
Med 2016;57:544-550

19. Amin MB, Edge S, Greene F, Byrd DR, Brookland RK, Washington MK, et al. AJCC cancer staging manual, 8th ed. New York: Springer International Publishing, 2017:203-220

20. Fujiya K, Tokunaga M, Makuuchi R, Nishiwaki N, Omori H, Takagi W, et al. Early detection of nonperitoneal recurrence may contribute to survival benefit after curative gastrectomy for gastric cancer. Gastric Cancer 2017;20:141-149

21. Hothorn T, Lausen B. On the exact distribution of maximally selected rank statistics. Comput Stat Data Anal 2003;43:121137

22. Shiraishi N, Inomata M, Osawa N, Yasuda K, Adachi Y, Kitano $S$. Early and late recurrence after gastrectomy for gastric carcinoma. Univariate and multivariate analyses. Cancer 2000;89:255-261

23. Facciorusso A, Del Prete V, Antonino M, Crucinio N, Neve V, Di Leo $A$, et al. Post-recurrence survival in hepatocellular carcinoma after percutaneous radiofrequency ablation. Dig Liver Dis 2014;46:1014-1019

24. Lee K, Kim HR, Kim DK, Kim YH, Park SI, Choi SH, et al. Postrecurrence survival analysis of stage I non-small-cell lung cancer. Asian Cardiovasc Thorac Ann 2017;25:623-629

25. Yoshida K, Kajiyama H, Utsumi F, Niimi K, Sakata J, Suzuki $S$, et al. A post-recurrence survival-predicting indicator for cervical cancer from the analysis of 165 patients who developed recurrence. Mol Clin Oncol 2018;8:281-285

26. Sopik V, Sun P, Narod SA. Predictors of time to death after distant recurrence in breast cancer patients. Breast Cancer Res Treat 2019;173:465-474

27. Sprinz C, Zanon M, Altmayer S, Watte G, Irion K, Marchiori E, et al. Effects of blood glucose level on $18 \mathrm{~F}$ fluorodeoxyglucose (18F-FDG) uptake for PET/CT in normal organs: an analysis on 5623 patients. Sci Rep 2018;8:2126

28. Pak KH, Yun M, Cheong JH, Hyung WJ, Choi SH, Noh SH. Clinical implication of FDG-PET in advanced gastric cancer with signet ring cell histology. J Surg Oncol 2011;104:566570

29. Yoon HJ, Kim BS, Moon CM, Yoo J, Lee KE, Kim Y. Prognostic value of diffuse splenic FDG uptake on PET/CT in patients with gastric cancer. PLoS One 2018;13:e0196110

30. Lee S, Oh SY, Kim SH, Lee JH, Kim MC, Kim KH, et al. Prognostic significance of neutrophil lymphocyte ratio and platelet lymphocyte ratio in advanced gastric cancer patients treated with FOLFOX chemotherapy. BMC Cancer 2013;13:350 31. Kim EY, Lee JW, Yoo HM, Park CH, Song KY. The platelet- to-lymphocyte ratio versus neutrophil-to-lymphocyte ratio: which is better as a prognostic factor in gastric cancer? Ann Surg Oncol 2015;22:4363-4370

32. Zhang Y, Lu JJ, Du YP, Feng CX, Wang LQ, Chen MB. Prognostic value of neutrophil-to-lymphocyte ratio and platelet-tolymphocyte ratio in gastric cancer. Medicine (Baltimore) 2018;97:e0144

33. Ryu SW, Kim IH. Comparison of different nutritional assessments in detecting malnutrition among gastric cancer patients. World J Gastroenterol 2010;16:3310-3317

34. Aoyama T, Sato T, Maezawa Y, Kano K, Hayashi T, Yamada T, et al. Postoperative weight loss leads to poor survival through poor S-1 efficacy in patients with stage II/III gastric cancer. Int J Clin Oncol 2017;22:476-483

35. Son YG, Kwon IG, Ryu SW. Assessment of nutritional status in laparoscopic gastrectomy for gastric cancer. Transl Gastroenterol Hepatol 2017;2:85

36. Vander Heiden MG, Cantley LC, Thompson CB. Understanding the Warburg effect: the metabolic requirements of cell proliferation. Science 2009;324:1029-1033

37. Yuan LW, Yamashita H, Seto Y. Glucose metabolism in gastric cancer: the cutting-edge. World J Gastroenterol 2016;22:20462059

38. Lin LL, Hsia CR, Hsu CL, Huang HC, Juan HF. Integrating transcriptomics and proteomics to show that tanshinone IIA suppresses cell growth by blocking glucose metabolism in gastric cancer cells. BMC Genomics 2015;16:41

39. Maher JC, Krishan A, Lampidis TJ. Greater cell cycle inhibition and cytotoxicity induced by 2-deoxy-D-glucose in tumor cells treated under hypoxic vs aerobic conditions. Cancer Chemother Pharmacol 2004;53:116-122

40. Wang TA, Xian SL, Guo XY, Zhang XD, Lu YF. Combined 18F-FDG $\mathrm{PET} / \mathrm{CT}$ imaging and a gastric orthotopic xenograft model in nude mice are used to evaluate the efficacy of glycolysistargeted therapy. Oncol Rep 2018;39:271-279

41. Cheong JH, Park ES, Liang J, Dennison JB, Tsavachidou D, Nguyen-Charles $C$, et al. Dual inhibition of tumor energy pathway by 2-deoxyglucose and metformin is effective against a broad spectrum of preclinical cancer models. Mol Cancer Ther 2011;10:2350-2362

42. Sunderland JJ, Christian PE. Quantitative PET/CT scanner performance characterization based upon the society of nuclear medicine and molecular imaging clinical trials network oncology clinical simulator phantom. J Nucl Med 2015;56:145-152 